\title{
Maternal and perinatal outcome associated with pregnancy induced hypertension
}

\author{
Vasavi Kolluru*, Ramya Y. Harika, Rajesh Kaul
}

Department of Obstetrics and Gynaecology, Kamineni Institute of Medical Sciences, Nalgonda, Telangana, India

Received: 21 August 2016

Revised: 24 August 2016

Accepted: 27 August 2016

\author{
*Correspondence: \\ Dr. Vasavi kolluru, \\ E-mail: vasavimdco@yahoo.com
}

Copyright: () the author(s), publisher and licensee Medip Academy. This is an open-access article distributed under the terms of the Creative Commons Attribution Non-Commercial License, which permits unrestricted non-commercial use, distribution, and reproduction in any medium, provided the original work is properly cited.

\begin{abstract}
Background: Pregnancy Induced hypertension continues to be rampant globally and is associated with high perinatal and maternal mortality and morbidity.

Methods: All patients beyond 20 weeks of pregnancy with pregnancy induced hypertension admitted in Kamineni Institute of Medical Sciences during the one year study period were enrolled in the study. The objective of the study was to analyse the cases of gestational hypertension, pre-eclampsia and eclampsia and their maternal outcome in terms of mode of delivery and complications. Perinatal outcome in relation to birth weight, APGAR and complications was also studied. The mean and standard deviation for socio-demographic variables, risk factors and symptomatology variables were analysed.

Results: Total hypertensive cases accounted for $234(7.9 \%)$ of the total deliveries; out of which gestational hypertension were 63 cases, preeclampsia 146 and eclampsia 25 cases, accounting for $(2.1 \%),(4.9 \%)$ and $(0.9 \%)$ of all deliveries. Commonest maternal complication was HELLP syndrome 8 cases $(3.4 \%)$ and there was no maternal mortality in our study. Total number of preterm deliveries were $74(3.47 \%)$. Perinatal mortality was seen in 54 cases (23\%). IUGR was the commonest foetal complication 78 cases $(33.4 \%)$.

Conclusions: Though the incidence of pre-eclampsia and eclampsia is on the decline, still it remains the major contributor to poor maternal and fetal outcome. Regular antenatal check-ups, early diagnosis, prompt multidisciplinary treatment, optimum timing of delivery reduces the incidence of complications and the maternal mortality. Early referral to and management of these cases at centers with advanced neonatal facilities will reduce the perinatal mortality.
\end{abstract}

Keywords: Gestational hypertension, Pre-eclampsia, Eclampsia

\section{INTRODUCTION}

Pregnancy induced hypertension is a common medical disorder of pregnancy, which along with hemorrhage and infection, results in much of the maternal morbidity and mortality. ${ }^{1}$ New onset hypertension termed gestational hypertension is followed by signs and symptoms of preeclampsia almost half of the time, according to Martin et al, pre eclampsia is identified in $3.9 \%$ of all pregnancies while by Berg and Colleagues, $12.3 \%$ of 4693 pregnancy related deaths in United States from 2003-07 were from complications of pregnancy induced hypertension. ${ }^{1}$

\section{Pre-eclampsia}

Incidence in hospital practice in India: varies widely from 5-15\%; (primigravida-10\%; multigravida-5\%). Perinatal mortality due to pre-eclampsia still remains high to the 
extent of $20 \%$, about $50 \%$ of which being stillborn in developing countries. ${ }^{2}$

\section{Eclampsia}

Hospital incidence in India ranges from $1 / 500$ to $1 / 30$, more in primigravida (75\%). Perinatal mortality is to the extent of $30-50 \%$. Maternal mortality in India ranges from $2-30 \%$. However if treated early and adequately, the mortality should be even less than $2 \%{ }^{2}$

The management of gestational hypertension, preeclampsia and eclampsia has gone through many changes and has achieved good results with the introduction of newer anti-hypertensives, different regimes of anticonvulsants and also increased awareness among the population.

This study is undertaken to analyze the cases of pregnancy induced hypertension, and to know the maternal and perinatal morbidity and mortality in rural population in the present times.

\section{METHODS}

Prospective analytical study was done at Department of Obstetrics and Gynaecology, Kamineni Institute of Medical Sciences, Narketpally, between June 2015 to May 2016.

\section{Inclusion criteria}

- Patients beyond 20 weeks of pregnancy with pregnancy induced hypertension.

\section{Exclusion criteria}

- Chronic hypertension, chronic renal disease, coarctation of aorta, endocrine disorders. (diabetes mellitus, pheochromocytoma, thyrotoxicosis), connective tissue diseases(lupus erythematosus) and patient refusal.

A total number of 234 cases of pregnancy induced hypertension (gestational hypertension, pre-eclampsia and eclampsia) admitted to Kamineni Medical College, Narketpally during the study period were enrolled after obtaining written informed consent. All patients were subjected to detailed history taking, general physical examination, thorough systemic and obstetric examination. Blood pressure was measured using the auscultatory method with a standard caliberated, validated instrument. An appropriate sized cuff was used to ensure accuracy, korottkoff sound 5 was taken to measure diastolic BP. The necessary investigations were sent. The patients were categorised into Gestational hypertension, pre eclampsia and eclampsia. Antihypertensives, anticonvulsants if necessary, were started and obstetric management was done according to the standard protocol.
All the sociodemographic variables were noted and the maternal outcomes were analysed in all the cases in terms of mode of delivery and development of complications like HELLP syndrome, acute renal failure, postpartum haemorrhage, abruptio placentae, pulmonary oedema and cerebral haemorrhage. Neonatal assessment was done by APGAR score at one minute and 5 minutes. Birth weights, neonatal intensive care unit (NICU) admission, IUD, IUGR2, stillbirth and other complications were noted. This information was subjected to computer analysis using SPSS (statistical package for social science) system. The mean and standard deviation for Socio demographic, risk factors and Symptomatology variables were analyzed.

\section{RESULTS}

A total number of 2949 deliveries were conducted at Kamineni Institute of Medical sciences, Narketpally from June 2015 to May 2016. Out of these, 234 (7.9\%) women had pregnancy induced hypertension. There were 63 cases of gestational hypertension which accounted for $(2.1 \%)$ of the total deliveries. 146 women had pre eclampsia, constituting $(4.9 \%)$ of the deliveries. Eclampsia was seen in 25 women accounting for $(0.9 \%)$ of the deliveries conducted (Table 1).

Table 1: Different types of pregnancy induced hypertension $(\mathrm{n}=\mathbf{2 3 4})$.

\begin{tabular}{|lll|}
\hline Types of PIH & No of cases (n) & Percentage \\
\hline $\begin{array}{l}\text { Gestational } \\
\text { hypertension }\end{array}$ & 63 & $27.3 \%$ \\
\hline $\begin{array}{l}\text { Severe } \\
\text { preeclampsia }\end{array}$ & 70 & $29.2 \%$ \\
\hline Preeclampsia & 76 & $32.4 \%$ \\
\hline Eclampsia & 25 & $11.1 \%$ \\
\hline Total & 234 & $100 \%$ \\
\hline
\end{tabular}

Table 2: Distribution of the sociodemographic factors $(\mathbf{n}=\mathbf{2 3 4})$.

\begin{tabular}{|lll|}
\hline Factor & No. of cases (n) & Percentage \\
\hline Age (years) & \multicolumn{2}{l|}{} \\
\hline $18-26$ & 173 & $73.9 \%$ \\
\hline $27-35$ & 60 & $25.6 \%$ \\
\hline $36-44$ & 1 & $0.4 \%$ \\
\hline Socio-economic status & \\
\hline Upper & 2 & $1 \%$ \\
\hline Middle & 54 & $23 \%$ \\
\hline Lower & 178 & $76 \%$ \\
\hline Parity & & \\
\hline Primi & 113 & $48.3 \%$ \\
\hline Multi & 119 & $50.9 \%$ \\
\hline Grandmulti & 2 & $0.9 \%$ \\
\hline Antenatal visits & & \\
\hline Unbooked & 129 & $54.9 \%$ \\
\hline Booked & 105 & $45.1 \%$ \\
\hline
\end{tabular}


The mean age of the study population was $23.52 \pm 4.33$ (mean \pm SD). $54.9 \%$ of the cases were unbooked (Table 2). Majority of them (76\%) belonged to low socioeconomic status. primigravidae constituted $48.3 \%$ of the study population while $51.7 \%$ were multigravidae. The mean gestational age of the study group was $36.50 \pm 2.47 \mathrm{SD}$. Systolic blood pressure of more than $160 \mathrm{~mm}$ of $\mathrm{Hg}$ was seen in $23.9 \%$ of the women and $16.2 \%$ of them showed diastolic blood pressures of more than $110 \mathrm{mmHg}$. Abnormal liver function tests were seen in $26.49 \%$ of the cases. $4.3 \%$ of them showed low platelet counts.

Table 3: Distribution of cases according to the mode of delivery $(n=234)$.

\begin{tabular}{|ll|l|}
\hline Mode of delivery & No. of cases (n) & Percentage \\
\hline Vaginal delivery & 98 & $41.9 \%$ \\
\hline $\begin{array}{l}\text { Outlet forceps } \\
\text { delivery }\end{array}$ & 17 & $7.3 \%$ \\
\hline Vacuum delivery & 2 & $0.9 \%$ \\
\hline Cesarean Section & 117 & $50.0 \%$ \\
\hline Total & 234 & 100.0 \\
\hline
\end{tabular}

In our study the number of vaginal deliveries were equal to caesarean sections. Total number of women who delivered vaginally were 177 out of which 17(7.3\%) were outlet forceps deliveries and $2(0.9 \%)$ were vacuum assisted vaginal deliveries. Total number of caesarean deliveries were 117 (50\%) (Table 3).

Table 4: Distribution of cases according to maternal complications $(\mathrm{n}=19)$.

\begin{tabular}{|lll|}
\hline Complications & $\begin{array}{l}\text { Booked(n) } \\
(129 \text { cases) }\end{array}$ & $\begin{array}{l}\text { Un-booked (n) } \\
(105 \text { cases) }\end{array}$ \\
\hline HELLP & 2 & 6 \\
\hline Acute renal failure & 1 & 2 \\
\hline $\begin{array}{l}\text { Post-partum } \\
\text { haemorrhage }\end{array}$ & 1 & 2 \\
\hline Abruptio placentae & - & 1 \\
\hline Pulmonary oedema & - & 2 \\
\hline $\begin{array}{l}\text { Cerebral } \\
\text { haemorrhage }\end{array}$ & - & 2 \\
\hline
\end{tabular}

Table 5: Distribution of babies according to complications and perinatal outcome $(n=114)$.

\begin{tabular}{|lll|}
\hline Complications & No. of cases (n) & Percentage \\
\hline IUGR & 78 & $33.4 \%$ \\
\hline Low birth weight & 127 & $54.2 \%$ \\
\hline Pre-Term & 74 & $31.6 \%$ \\
\hline Hypoxia & 24 & $10.2 \%$ \\
\hline MAS & 5 & $2.1 \%$ \\
\hline ARDS & 7 & $2.9 \%$ \\
\hline Perinatal mortality & 54 & $23.07 \%$ \\
\hline
\end{tabular}

HELLP syndrome was the commonest maternal complication in our study, seen in 8 cases $(3.4 \%)$ followed by acute renal failure (1.28\%). Post-partum haemorrhage was seen in 3 cases and abruption placentae was seen in one case. 2 cases developed pulmonary oedema and cerebral haemorrhage (Table 4). All complicated cases were promptly managed with a multidisciplinary approach and were successfully treated. There was no maternal mortality in the present study.

Out of the 234 deliveries, $74(31.6 \%)$ were pre term births (Table 5). There were 54 (23.1\%) cases of perinatal mortality with 35 intra uterine deaths and 19 early neonatal deaths (Table 5).

Majority of the cases (82.4\%) had Apgar score between 5-7 at one minute and Apgar score of 8-10 at five minutes in $80.2 \%$ of cases. In the present study the mean birth weight was $2.35 \mathrm{~kg}$ with standard deviation of 0.76 . Most common foetal complication was Low birth weight (54.2\%) followed by Intra uterine growth restriction seen in $33.4 \%$ of cases (Table 5). In our study 99 babies $(42.3 \%)$ needed NICU admission.

\section{DISCUSSION}

Pregnancy induced hypertension is a common condition which is responsible for majority of maternal and fetal morbidity and mortality. The incidence of pregnancy induced hypertension (specially pre-eclampsia and eclampsia) and the total number of deaths from the same have come down dramatically in developed countries. This is totally attributed to improvements in prenatal care and management. However, in developing countries it still stands as one of the major complications of pregnancy.

In this study the overall incidence of pregnancy induced hypertension was $7.9 \%$. It is on the lower side when compared with other studies (Table 6).

Table 6: Comparison of incidence of pregnancy induced hypertension with other studies.

\begin{tabular}{|lll|}
\hline Author $/$ Source & year & Incidence \\
\hline Asbagh and Khan, Stone et al. & 1996 & $5-18.5 \%$ \\
\hline Alokendu Chatterjee, Geeta Basu & 2000 & $10 \%$ \\
\hline Girija et al & 2001 & $11.7 \%$ \\
\hline $\begin{array}{l}\text { Shirish N Daftary and Sudip } \\
\text { Chakravarti }\end{array}$ & 2007 & $10-15 \%$ \\
\hline Bangal V et al $^{5}$ & 2012 & $8.96 \%$ \\
\hline${\text { Gandhi M et } \mathrm{al}^{9}}^{\text {Present study }}$ & 2015 & $12.8 \%$ \\
\hline
\end{tabular}

Incidence of gestational hypertension in this study was $2.1 \%$ which is quite similar to the study by Martin and colleagues (National center for health statistics 2002) that showed an incidence of $3.7 \%$. $^{1}$ Incidence of preeclampsia in this study was $4.9 \%$. which is comparable but less than the incidence in the studies done by Chhabra $\mathrm{S}$ et al 5.2\% and Sundaram S 5\% and by Bangal V et al 
$7.26 \% .^{3-5}$ In the present study, the incidence of eclampsia was $0.9 \%$ which is more or less the same showing a marginally decreasing trend compared to studies done over the past 10 years. This may be attributed to increased awareness, early diagnosis and prompt treatment of pre eclampsia. In the present study most of the women $(76 \%)$ were from the low socio- economic status. All patients with eclampsia were from low socioeconomic status and in the study done by Parmar MT et al $51 \%$ of patients were from low socio economic status. ${ }^{6}$ This indicates that socio-economic status, poor nutrition and inadequate antenatal care have close relationship with preeclampsia and eclampsia. In this present study number of vaginal deliveries $117(50 \%)$ were equal to the number of caesarean deliveries $117(50 \%)$ which is similar to the study done by Uddin AW et al. ${ }^{7}$ In which the rate of cesarean section is about $50.8 \%$ where as in the studies done by Bangal $\mathrm{V}$ et al and by Parmar MT et al is $35 \%$ and $37 \%$ respectively (Table 7). ${ }^{5,6}$ This comparatively higher rate of caesarean section in our study is attributed to the fact that our institution is a tertiary referral centre situated in the rural area and most of the patients were referred after development of complications.

Table 7: Comparison of mode of delivery of cases with other studies.

\begin{tabular}{|c|c|c|c|c|}
\hline Author & $\begin{array}{l}\text { Parmar MT et al }{ }^{6} \\
n=100\end{array}$ & $\begin{array}{l}\text { Bangal V et } \text { al }^{5} \\
n=100\end{array}$ & 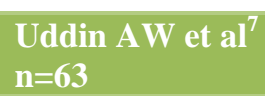 & Present study $n=234$ \\
\hline Vaginal & $63 \%$ & $59 \%$ & $38.1 \%$ & $41.9 \%$ \\
\hline Outlet forceps & - & $4 \%$ & $6.3 \%$ & $7.3 \%$ \\
\hline Vaccum & - & $2 \%$ & $4.8 \%$ & $0.9 \%$ \\
\hline Cesarean section & $37 \%$ & $35 \%$ & $50.8 \%$ & $50 \%$ \\
\hline
\end{tabular}

Table 8: Comparison of maternal complications of cases with other studies.

\begin{tabular}{|lllll|}
\hline $\begin{array}{l}\text { Maternal } \\
\text { complications }\end{array}$ & $\begin{array}{l}\text { Minire A et al } \\
\mathbf{n = 4 3 0}\end{array}$ & Zanette E et al & $\begin{array}{l}\text { Gandhi M et al } \\
\mathbf{n}=\mathbf{9 5}\end{array}$ & $\begin{array}{l}\text { Present study } \\
\mathrm{n=234}\end{array}$ \\
\hline HELLP syndrome & $4.2 \%$ & - & $5(5.26 \%)$ & $8(3.4 \%)$ \\
\hline Acuterenal failure & $12.3 \%$ & - & $1(1.05 \%)$ & $3(1.2 \%)$ \\
\hline Postpartum haemorrhage & - & $4.0 \%$ & $5(5.26 \%)$ & $3(1.2 \%)$ \\
\hline Abruptio placenta & $7 \%$ & $3.6 \%$ & $5(5.26 \%)$ & $1(0.4 \%)$ \\
\hline Pulmonary edema & $5.6 \%$ & $1.7 \%$ & - & $2(0.8 \%)$ \\
\hline
\end{tabular}

Table 9: Comparison of fetal outcome with other studies.

\begin{tabular}{|c|c|c|c|c|}
\hline & $\begin{array}{l}\text { Bangal V. et al } \\
n=100\end{array}$ & $\begin{array}{l}\text { Uddin } \mathrm{AW} \text { et } \text { al }^{7} \\
\mathrm{n}=63\end{array}$ & $\begin{array}{l}\text { Gandhi M etal }{ }^{9} \\
\mathrm{n}=95\end{array}$ & $\begin{array}{l}\text { Present study } \\
\mathrm{n}=234\end{array}$ \\
\hline IUGR & $20 \%$ & $33.3 \%$ & & $33.4 \%$ \\
\hline Preterm & $37 \%$ & & $29 \%$ & $31.6 \%$ \\
\hline Hypoxia & - & - & & $10.2 \%$ \\
\hline MAS & - & - & & $2.1 \%$ \\
\hline ARDS & - & - & & $2.9 \%$ \\
\hline
\end{tabular}

Table 10: Comparison of perinatal mortality with other studies.

\begin{tabular}{|c|c|c|c|c|c|}
\hline Author & $\begin{array}{l}\text { Nisar, } N \text { et } \text { al }^{11} \\
n=63\end{array}$ & $\begin{array}{l}\text { Goswami P et al } \\
n=40\end{array}$ & $\begin{array}{l}\text { George JN et al } \\
n=100\end{array}$ & $\begin{array}{l}\text { Kiondo P } \\
\text { et } \mathrm{al}^{13} \mathrm{n}=171\end{array}$ & $\begin{array}{l}\text { Present study } \\
\mathrm{n}=234\end{array}$ \\
\hline Perinatal mortality & $23 \%$ & $25 \%$ & $29 \%$ & $22 \%$ & $23 \%$ \\
\hline
\end{tabular}

HELLP syndrome is characterized by hemolysis, elevated liver enzymes and low platelet counts. ${ }^{16}$ It was the commonest complication in our study. In this study 8 women developed HELLP syndrome giving a incidence of $3.4 \%$. The incidence of acute renal failure was $12.3 \%$ in Minire A et al study compared to $1.28 \%$ in our study similarly incidence of abruption (7\%) and pulmonary edema $(5.6 \%)$ was also high in their study compared to ours (Table 8). The overall complication rate was less in our study compared to the complications seen in other studies probably because of more number of booked cases in our study, which allowed early detection and adequate treatment of preeclampsia. In the present study, total number of preterm deliveries was 74 (31.6\%). Eclampsia was responsible for maximum number of preterm deliveries $58.3 \%$ followed by severe preeclampsia $50 \%$, which is comparable with the studies by Gandhi $\mathrm{M}$ et al, Bangal $\mathrm{V}$ et al and by George JN et al 
where in, the incidence was $29 \%, 37 \%$, and $31 \%$ respectively (Table 9)..$^{5,9,10}$ This indicates that severity of the disease is directly related to the prematurity of the baby. 32 out of 182 cases in this study had Apgar <6 $(17.5 \%)$ at $1 \mathrm{~min}$ and 22 out 182 cases in this study had Apgar $<8(11.9 \%)$ at 5 minutes.

IUGR was the commonest complication totaling up to 78 cases $(33.4 \%)$ which is comparable with studies by Bangal V. et al and by Uddin AW et al in which the incidence of IUGR is $20 \%$ and $33.3 \%$ respectively (Table 9). ${ }^{5,7}$ Total $99(42.3 \%)$ babies needed NICU admission, out of which 23 babies needed ventilator support. The perinatal mortality in our study is comparable with studies done by Nisar $\mathrm{N}$ et al $(23 \%)$, Goswami P et al (25\%), George JN et al (29\%), Kiondo P et al $(22 \%)$. Bangal $\mathrm{V}$. et al suggested that maternal and fetal morbidity and mortality can be reduced by early recognition and institutional management (Table 10). ${ }^{10-13}$

\section{CONCLUSION}

Pre-eclampsia and Eclampsia still remains a major problem in developing countries. Pregnancy induced hypertension is one of the most extensively researched subjects in obstetrics. Still the etiology remains an enigma to us. Though the incidence of pre-eclampsia and eclampsia is on the decline, still it remains the major contributor to poor maternal and foetal outcome. The fact that pre-eclampsia, eclampsia is largely a preventable disease is established by the negligible incidence of preeclampsia and eclampsia with proper antenatal care and prompt treatment of pre-eclampsia. In pre-eclampsia and eclampsia, pathology should be understood and that it involves multiorgan dysfunction should be taken into account. The early use of antihypertensive drugs, optimum timing of delivery and strict fluid balance, anticonvulsants in cases of eclampsia will help to achieve successful outcome. Early transfer to specialist centre is important and the referral the referral centers should be well equipped to treat such critically ill patients.

Training and continuing medical education of the attending staff and structuring management protocols relevant to local needs is also an important part in case of $\mathrm{PIH}$.

\section{ACKNOWLEDGEMENTS}

Authors would like to thank all the staff of department of obstetrics and gynaecology at Kamineni Institue of Medical Sciences and all the subjects for participating in the study.
Funding: No funding sources Conflict of interest: None declared

Ethical approval: The study was approved by the Institutional Ethics Committee

\section{REFERENCES}

1. Cunningham FG, Lenovo KJ, Bloom SL, Hauth JC, Rouse DJ, Catherine YS. Williams Obstetrics. $24^{\text {th }}$ ed. New York, NY : Mc Graw Hill Companies;2014.

2. Dutta DC. Hypertensive disorders in pregnancy. In: Dutta DC. Textbook of Obstetrics.8th ed. Kolkata. Jaypee Publishers;2014.

3. Chhabra S, Gandhi D. Prediction of pregnancy induced hypertension/preeclampsia by detecting microablubminuria. J Obst and Gyn India. 2002.

4. Sundaram S, Pratibha D. Pathogenesis of pregnancy induced hypertension. Obstet Gynecol. 2003;8(12)671-4.

5. Bangal V, Giri P, Mahajan A. Maternal and foetal outcome in pregnancy induced hypertension: a study from rural tertiary care teaching hospital in India. Int J Biomed Res. 2012;2(12):595-99.

6. Parmar, Mehul T, Solanki HM, Vibha V. Gosalia. Study of risk factors of perinatal death inpregnancy induced hypertension (PIH).Community Med. 2012;3(4):703-7.

7. Uddin A, Chowdhury S, Chowdhury S. Hypertensive Disorders of pregnancy and its outcome in a tertiary care hospital. Int J Gynecology Obst. 2012;119:821.

8. Berry E, Iqbal S. HELLP syndrome at 17 weeks gestation: a rare and catastrophic phenomenon. J Clinical Gyne Obst. 2014;3(4):147-150.

9. Gandhi M, Jani P, Patel U, Kakani C, Thakor N, Gupta N. Perinatal outcome in pregnancy induced hypertension cases at GMERS medical college, Dharpur-Patan, North Gujarat region, India: a prospective study. Int J Adv Med. 2015;2(2):152.

10. George JN, Amaresh A. Neonatal mortality and morbidity in pregnancy induced hypertension: a prospective observational study. J Evolution Med Dental Sci. 2014;3(19):5238-46.

11. Nisar N, Memon A, Sohoo NA, Ahmed M. Hypertensive disorders of pregnancy: frequency, maternal and fetal outcomes. Pakistan Armed Forces Med J. 2010;1(3):112-6.

12. Goswami P, Lata H, Memon S, Khaskhelli LB. Excessive placental calcification observed in PIH patients and its relation to fetal outcome. JLUMHS. 2012;11(3):144-8.

13. Kiondo P, Tumwesigye N, Wandabwa J, WamuyuMaina G, Bimenya G. Adverse neonatal outcomes in women with pre-eclampsia in Mulago Hospital, Kampala, Uganda: a cross-sectional study. Pan African Medical Journal. 2014;17.

Cite this article as: Kolluru V, Harika RY, Kaul R. Maternal and perinatal outcome associated with pregnancy induced hypertension. Int J Reprod Contracept Obstet Gynecol 2016;5:3367-71. 